\title{
Can a Developing Country Support the Welfare Needs of Children Affected by AIDS? A Perspective from Tanzania
}

\author{
Valerie Leach ${ }^{*}$
}

\begin{abstract}
1 Introduction
Can Tanzania support the welfare needs of children affected by HIV/AIDS? The short answer to this question is, yes it can. Tanzania has a programme to support the 'most vulnerable children'. One deeper question concerns the extent of support which can and will be provided, including that from the government budget. The programme which is costed here would provide only modest assistance and while it undoubtedly would help improve the outcomes for very poor and vulnerable children, it is questionable whether it covers enough children and gives them enough assistance to be truly said to meet their welfare or social protection needs. A second deeper question is whether 'children affected by HIV/AIDS' warrant special support beyond that which would be available for children who are most vulnerable for whatever reason. Moreover, support specifically targeted at children affected by AIDS runs the risk of being stigmatising and discriminatory, even if it were practically feasible.
\end{abstract}

\section{Children affected by AIDS in Tanzania 2.1 National data}

The overall rate of infection in adults in Tanzania is 7-7.7 per cent among women and 6.3 per cent among men according to the Tanzania HIV Indicator Survey (THIS) 2003-04 (TACAIDS 2005). ${ }^{1}$ Some areas, such as Mbeya, Iringa and Dar es Salaam have prevalence rates exceeding 10 per cent. Orphanhood is highest in these regions too. Eleven per cent of the population under 18 have lost one or both parents according to the Population and Housing Census 2002 (National Bureau of Statistics et al. 2002). In a population of 36 million, about 2 million children have lost a parent and just over 1 per cent of children have lost both parents. UNAIDS/World Health Organization (WHO) (2006) estimate that AIDS is responsible for about half of total orphan numbers. THIS also surveyed vulnerable children (defined as children with one or both parents very sick for at least three months in the 12 months prior to the survey or children living in a household with no adult aged 18-59). Orphans and vulnerable children (OVC) together were 16 per cent of the child population overall. However, under these definitions of orphaning and vulnerability, there is a weak match with indicators of poverty.

\section{By age, OVC are a smaller percentage of the} youngest age group and a much larger percentage of older children. OVCs were 7 per cent of the underfives and 30 per cent of 15-17 year olds.

There is much geographical variation. The areas with higher prevalence of HIV are not those with either the highest rates of child mortality or the highest levels of poverty. HIV prevalence is 10.9 per cent in urban areas and 5.3 per cent among rural adults. Adults in the least poor quintile have 10.5 per cent HIV prevalence, those in the poorest quintile have 3.4 per cent.

People in urban areas have much easier access to services and support than those in rural areas. THIS (TACAIDS 2005) reported the percentage of OVC in households having received support in the 12 months preceding the survey. Eight per cent of urban 
children and 3-5 per cent of rural children got medical, emotional, or material support from sources other than family or friends. Successive Demographic and Health Surveys (DHS) conducted in Tanzania over 15 years report higher access to health services among urban households than rural, lower rates of child mortality and malnutrition in urban households. The most recent household budget survey, 2000-1, also shows a much lower rate of household income poverty in urban households, especially in Dar es Salaam, than in rural households, and that the reduction in income poverty over the 1990s was essentially confined to urban households, especially those in Dar es Salaam.

Therefore, to the extent that orphanhood is a proxy for children affected by AIDS, they are generally no worse off and may indeed be in households that are often less poor than others. More specific data are needed to identify particularly vulnerable children, to illustrate the particular toll of HIV/AIDS and orphanhood on individual children and the extent to which they need support.

\subsection{Studies of orphaned children}

In a study of orphanhood in Kagera, started in 1991 at a time when Kagera was considered the epicentre of HIV/AIDS in Tanzania, children who were not orphaned at that time were followed up again in 2004 (Beegle et al. 2005). By then, 23 per cent of them had lost one or both parents before they reached the age of 15. Maternal orphans were more likely to be stunted and lose years of education. Paternal orphans, more common than maternal orphans, were less affected. Older children and those already in school were less likely to suffer from these adverse outcomes than children who had been orphaned at a younger age and who had not yet started school.

Research undertaken by the National Institute for Medical Research (NIMR), Mwanza Centre, compared the circumstances of orphaned and other children and their care providers. The researchers found that orphans appear to be more vulnerable than children in nuclear families, and that foster children are relatively less vulnerable to disadvantage than orphans but show evidence of reduced wellbeing across most indicators compared with children in nuclear families. Certain subgroups of orphans are more vulnerable than others: their sex and age, the sex of the deceased parent and the sex and age of the principal caregiver are determining factors Nonetheless, the researchers note that the level of relative disadvantage of orphans and foster children is slight compared with the level of need of all children (NIMR n.d.).

A study of orphans in Bukoba rural district, Kagera region, and in Makete district, Iringa region, showed that their experiences were quite varied. In Bukoba a wealth of community organisations provides various forms of social insurance that mitigate the adverse impacts of HIV/AIDS on households. Existing data from surveys undertaken in Kagera from the 1980s onwards indicate that the epidemic initially affected better off (more mobile, more affluent, and larger) households, and that the measurement of the social and economic impacts of HIV/AIDS is complicated by the fact that some urban people 'go home' to die, so that their final illness and death are registered in their host household rather than their own household. Partly for these reasons, affected households in Bukoba often have more assets, higher incomes and are larger than non-affected households.

In Makete, the socioeconomic impacts of HIV/AIDS were found in both the least poor 20 per cent and the poorest 20 per cent of households. The household survey in Makete distinguished between households affected by adult morbidity and mortality since 2000 (a proxy indicator for AIDS) and those not affected. There was an appreciable difference in livelihoods between affected and non-affected households. While all households relied on farming, the affected households were also more reliant on gifts and food, and the selling of labour for food, with the small number of child workers exclusively found among these affected households. In the more extreme cases, they tended to relocate household members. This implies that the rural affected households are adopting 'coping strategies' that leave them more vulnerable.

There were also differences between households fostering orphans and those not. Fostering households were poorer. Orphan fostering households were disproportionately represented in the poorest quintile of the population, few of them in the least poor quintile. They were eating fewer meals per day. Two-thirds of all fostering homes were female-headed. The combination of fostering an orphan and suffering adult morbidity or mortality showed starker differences. All the major responses 
Table 1 Estimated number of children by different vulnerability criteria, 2006

\begin{tabular}{|c|c|c|c|c|}
\hline Vulnerability criteria & $0-6$ years & $7-14$ years & $15-17$ years & Total \\
\hline Number of poor children & $3,126,362$ & $2,645,657$ & 841,304 & $6,613,324$ \\
\hline $\begin{array}{l}\text { Number of children in child-headed } \\
\text { households }\end{array}$ & 39,910 & 62,282 & 72,008 & 174,201 \\
\hline $\begin{array}{l}\text { Number of children in elderly headed } \\
\text { households }\end{array}$ & 69,445 & 163,671 & 59,765 & 292,882 \\
\hline Number of double orphaned children & 24,820 & 110,085 & 70,579 & 205,484 \\
\hline Number of maternal orphaned children & 79,723 & 216,980 & 115,420 & 412,123 \\
\hline Number of paternal orphaned children & 257,779 & 591,556 & 291,920 & $1,141,255$ \\
\hline Total number of orphans & 362,322 & 918,621 & 477,919 & $1,758,862$ \\
\hline Number of disabled children & 56,977 & 99,277 & 37,729 & 193,982 \\
\hline Most vulnerable & 181,689 & 481,439 & 265,815 & 928,944 \\
\hline
\end{tabular}

Lindeboom et al. (2007) using Tanzania National Projections (United Republic of Tanzania 2006) and Poverty and Human Development Report (United Republic of Tanzania 2005).

to stress, including diversion of adult labour, loss of income, assets and food, were heightened in this group (de Waal et al. 2004).

This study underscores the importance of understanding local and circumstantial factors which determine the extent to which communities, households and children will be affected by HIV/AIDS The findings from Tanzania are mirrored in the more general assessment provided by Maia Green (2005):

Poverty limits the capacities of families and individuals to care for household members. Differentials between orphan children and other children are less significant than those between poor and non poor households.... Where kinship bonds are strong and 'where families had adequate resources' orphan children do not necessarily fare worse than non-orphans [my emphasis], nor are their development outcomes very different .... The poverty of the household in which a child resides had greater impact on educational participation than orphan status ..., but double orphans fare worse than other children, across all households.

\section{Most vulnerable children}

Poverty is pervasive in Tanzania, with over one-third of households living below a basic needs poverty line, set in 2000/1 at TShs259 per adult equivalent per day, even in purchasing power parity terms well below '\$1 a day'. Nearly one-fifth live below the even lower food poverty line. This implies that such households do not command income sufficient even to provide enough food to satisfy their basic minimum nutritional requirements, with consequences for physical and mental development, economic and social wellbeing.

Estimates of the numbers of poor, orphaned and vulnerable children under different criteria have been generated using population census data and projected to 2006 (Table 1).

The 'most vulnerable children' (MVC) are defined here with a composite of vulnerability criteria using data which are available from the population census: (1) children living in child-headed households; (2) children living in elderly headed households with no adult aged 20-59 present; (3) children with both parents deceased; (4) (in rural areas) children with one surviving parent living in a house with very poor quality roofing (grass and/or mud) and/or children with a disability living in similarly poor conditions; and (5) (in urban areas) children with one surviving parent living in a house with very poor quality roofing (grass and/or mud) or with very poor wall materials or without toilet facilities and children with a disability living in similar very poor conditions.

The number of most vulnerable children living in poor conditions was estimated to be 929,000 in total: 736,000 in rural areas and over 193,000 in urban areas. This is 5 per cent of the child population: the poorest of the very poor. Note that this does not 
include all AIDS orphans, since some of them will live in less poor households. Nor is it even a majority of all the children who are very poor.

\section{Estimating a level of support for most vulnerable children}

The level of support which might be provided to MVC has been estimated. The direct support costs per child are estimated to be the amount of money which would be needed to raise the average per child expenditure of the poorest children (those living in households with expenditures more than 30 per cent below the poverty line) to the average level of expenditures on children living at about the national poverty level. Since about 40 per cent of children live at or below this level, it is unlikely that a national programme could finance support for vulnerable children above this level, and to do so would imply support for the most vulnerable at levels above the norm for most children in their communities.

The analysis shows that the gap in expenditure for food is by far the largest element of cost. In 2006, the cost of bridging the expenditure gap for the 930,000 children considered to be most vulnerable would be TShs37.8 billion (US $\$ 31.5$ million). Of this amount, TShs30.7 billion is needed for food, TShs7.1 billion for non-food items. With administrative costs estimated at 15 per cent, the total annual cost would be TShs43.5 billion (US\$36.2 million). The costs of establishing systems of identifying and providing support for the most vulnerable children through local authorities and partner organisations are estimated to be an average of about TShs50 million per district, a total for national coverage of about TShs6 billion (US\$4.7 million) (Lindeboom et al. 2007).

The total government budget in 2006/7 was TShs4,851 billion. These estimated annual costs for supporting the most vulnerable children are less than 1 per cent of this. The estimated budget for HIV/AIDS in 2006/7 was TShs390.3 billion. The estimated annual cost for supporting MVC is 11 per cent of this.

\section{Integrating support for the most vulnerable children}

These costs are certainly affordable, and from the government budget, though reallocations and changes in management practices will clearly be needed for full and effective implementation. There are issues related to the high proportion of expenditures on HIV/AIDS programmes which are externally funded and the manner in which these programmes are managed External financing accounts for close to 90 per cent of total public expenditures on HIV/AIDS (Foster and Smyth 2007). The US President's Emergency Plan for AIDS Relief (PEPFAR) alone accounts for 59 per cent of public spending on HIV/AIDS. It is 'off-budget' and managed through non-governmental organisations (NGOs).

Existing programmes of support for MVC are now coordinated through the Ministry of Health and Social Welfare and an implementing partners group, with international NGOs which direct the programmes and their external financing agencies. Most of the NGOs follow guidelines issued by the Department for Social Welfare for community-based programming. Though the largest gap in expenditures for MVC is for food, many of the programmes now in place are directly supporting individual MVC by providing non-food items, such as clothing, school uniforms, and building materials for shelter, at unit costs which far exceed the expenditures of households for other children, which is causing resentment and jealousy by children and undermining social cohesion in some communities (Mhamba et al. 2007). Where food stuffs are provided, they tend to be provided directly, incurring high transport costs. Moreover the number of children currently being provided support is in the tens of thousands, not close to the million who are most in need of support.

Funding through PEPFAR, the Global Fund, the World Bank's Multi-sectoral AIDS Project's Community HIV/AIDS Community Response Fund (CHRF) and Tanzania Social Action Fund's Village Funds available for support for MVC would cover most of the costs of a programme of support such as that costed above. If cash were to be made available for local purchase of locally produced food, the costs of providing food might also be reduced compared with unit costing in the World Food Programme (WFP) programme to support the nutritional requirements of children affected by HIV/AIDS. Modest assumptions may be made about contributions of communities to care for their MVC - examples of community farms in Makete are noteworthy, where produce is given to them. With these assumptions, the annual costs of modest support for close to 1 million children are within existing resourcing. 
Questions of national government responsibilities, funding and local management still need to be addressed, and there are useful recommendations from the recent HIV/AIDS public expenditure review, including (1) increase priority to prevention, and to the district and community response; (2) make longer term and more predictable aid commitments; and (3) launch budget support for HIV/AIDS, including allocation of funds to local government authorities through the budget, based on objective criteria (Foster and Smyth 2007). The analysis reported above provides the basis for such allocation.

\section{Most vulnerable children in the bigger picture}

The calculations above do not cover some of the welfare needs of the MVC. In the particular cases of healthcare and education, the estimates incorporate the average expenditures of households living close to the poverty line. The additional costs of ensuring access to healthcare and full participation in education of MVC have not been included. Compared with current government budgets for health and education, these additional costs are likely to be low.

In education, while government policy is to have children enrolled in primary school at seven years of age, most children are enrolled at an older age. Gross attendance rates in primary school of children in the poorest quintile of households are 82 per cent, compared with 116 per cent of children in the least poor quintiles (National Bureau of Statistics and ORC Macro 2005). Enrolment rates of poor vulnerable children are slightly lower than those of other children, with greater differences among urban vulnerable children (Lindeboom et al. 2007), where the marginal costs to the government budget of increasing school attendance would be modest. Reforms in funding primary education now allow for enrolment without fee and capitation grants based on school-age population, not the numbers of children enrolled. With more equitable support for the MVC and locally based structures of support for those most in need, their school attendance is more likely to be encouraged.

Access to basic preventive health services for young children is high - 75 per cent of children in the poorest quintile have been immunised with a third dose of DPT-Hb3 (Diptheria, Polio, Tetanus and Hepatitis B-3) vaccine, as have 90 per cent of less poor children. These services are provided without charge. The costs of curative services, in spite of policies which provide for exemptions and waivers, distance to health facilities, and costs of travel and waiting times, are such that poorer and rural households are less likely to use health facilities. The difference shows up most starkly in births taking place in health facilities, where the DHS in 2004-5 reported that 81 per cent of urban women delivered their babies in a health facility and only 39 per cent of rural women did so (National Bureau of Statistics and ORC Macro 2005). Health financing, shortages of health personnel, their geographic allocations and low productivity are larger chronic issues confronting health services. HIV/AIDS exacerbates them.

The children who are most directly affected by HIV/AIDS are those infected with the virus. In common with most other countries, Tanzania has been slow in rolling out universal access to prevention of mother-to-child transmission (PMTCT) and to paediatric antiretrovirals. UNAIDS/WHO estimates that there are 21,000-64,000 children in need of antiretroviral therapy, and 100,000-320,000 in need of the inexpensive cotrimoxazole. In 2005, only 6 per cent of HIV-infected pregnant women received antiretrovirals for PMTCT (UNAIDS/WHO 2006). More attention is being paid to these concerns and external financing is increasingly available to address them. The larger issues of the health infrastructure and staffing remain of great concern. Here again, external financing is supporting improvements, including a new World Bank programme of support for strengthening health systems (World Bank 2007).

Within this larger picture, it is not the financing and affordability of the support needed by MVC that is the main concern. The concern is much more the marginalisation of children generally and poor children in particular in the political economy of Tanzania. Attention is being paid to specific sectoral developments in education and health. Beyond that, there is no strong coherent perspective of the rights of children and state obligations, nor firm direction towards their realisation. Tanzania will continue to need external support in discharging these obligations, and especially for HIV/AIDS, ensuring access to appropriate preventive and curative care. The effective management of such support and the equitable allocation of all public resources require strong national management and structures. And a stronger profile for children and role of social assistance/protection in development strategy is needed. 
This is a tall order. There are many competing demands and the role of children as citizens is underplayed. But the consequences of not supporting the welfare needs of the most vulnerable children in Tanzania contribute to high rates of

\section{Notes}

* This article is based on an analysis reported in Lindeboom et al. (2007).

1 This is the most recent population-based survey data. Results from a new survey undertaken in

\section{References}

Beegle, K.; De Weerdt, J. and Dercon, S. (2005)

'Orphanhood and the Long-run Impact on Children', American Journal of Agricultural Economics 88.5: 1266-72

de Waal, A.; Tumushabe, J.; Mamdani, M. and Kilama, B. (2004) Changing Vulnerability to Crisis in Tanzania: Implications for Children and UNICEF Activities, report to UNICEF Tanzania, September Foster, M. and Smyth, R. (2007) Tanzania Public Expenditure Review Multi-Sectoral Review: HIV/AIDS, report prepared on behalf of HIV/AIDS PER Working Group, Tanzania Commission for AIDS (TACAIDS), Ministry of Finance and Government of Tanzania

Green, M. (2005) Strengthening National Responses to Children Affected by HIV/AIDS: What is the Role of the State and Social Welfare in Africa?, background paper prepared for UNICEF for Wilton Park Conference, 14-16 November

Lindeboom, W.; Mhamba, R.; Kilama, B. and Leach, V. (2007) Towards Revising the Costed National MVC Programme, report for the Ministry of Health and Social Welfare, Research on Poverty Alleviation (REPOA), Dar es Salaam, February

Mhamba, R.; Lindeboom, W.; Omondi, F. and Leach, V. (2007) 'Social Protection in the Context of the MVC Programme in Tanzania. An Assessment of the Impact of Implementing the MVC Programme and Operation of the MVC Funds and the Potential for Scaling up to Provide National Coverage of Social Protection for Children', unpublished report for UNICEF, Tanzania: Research on Poverty Alleviation (REPOA) mortality and malnutrition, large numbers of children growing up in destitution, and economic losses far in excess of the modest expenditures needed to provide support for them.

$2007 / 8$ are expected to be publicly available before the end of 2008.

National Bureau of Statistics and ORC Macro (2005) Tanzania Demographic and Health Survey 2004-2005

National Bureau of Statistics, Ministry of Planning, Economy and Empowerment, and United Republic of Tanzania Ministry of Planning (2002) Population and Housing Census, Dar es Salaam: United Republic of Tanzania

NIMR (National Institute for Medical Research) (n.d.), Mwanza Centre, Operational Research to Compare the Circumstances of Orphan and Non-orphan Children and their Care Providers in Mwanza, Tanzania, report for UNICEF Tanzania

TACAIDS (Tanzania Commission for AIDS), National Bureau of Statistics (NBS), and ORC Macro (2005) Tanzania HIV/AIDS Indicator Survey 2003-04

UNAIDS/WHO (2006) Epidemiological Fact Sheet for United Republic of Tanzania, www.unaids.org/en/ KnowledgeCentre/HIVData/Epidemiology/ epifactsheets (accessed August 2008)

United Republic of Tanzania, Population and Housing Census 2002 (2006) National Projections Volume VIII, December, Dar es Salaam: National Bureau of Statistics, Ministry of Planning, Economy and Empowerment

United Republic of Tanzania, Research and Analysis Working Group (2005) Poverty and Human Development Report, Dar es Salaam: United Republic of Tanzania

World Bank (2007) 'Healthy Development', The World Bank Strategy for HNP Results, Washington DC: World Bank 